
\title{
3 Research Square \\ The Effect of Positive Thinking Training on Anxiety and Happiness in the Elderly: a Quasi- Experimental Study
}

\section{Anis Pourdavarani}

Health in Disasters and Emergencies Research Center, Institute for Futures Studies in Health, Kerman University of Medical Sciences, Kerman, Iran.

\section{Jamileh Farokhzadian}

Nursing Research Center, Kerman University of Medical Sciences, Kerman, Iran.

\section{Mansooreh Azizzadeh Forouz}

Neuroscience Research Center, Institute of Neuropharmacology, Kerman University of Medical Science, Kerman, Iran.

\section{Sedigheh Khodabandeh Shahraki ( $\nabla$ s_khodabandeh@kmu.ac.ir)}

Department of Community Health Nursing, Razi Faculty of Nursing and Midwifery, Kerman University of Medical Sciences, Kerman, Iran

\section{Research Article}

Keywords: Education, Positive Thinking, Anxiety, Happiness, Elderly

Posted Date: September 15th, 2021

DOl: https://doi.org/10.21203/rs.3.rs-877610/v1

License: (9) This work is licensed under a Creative Commons Attribution 4.0 International License. Read Full License 


\section{Abstract}

Background: Anxiety and depression are the most common psychological disorders in the aging period. One of the ways to deal with anxiety and depression and increase happiness in the elderly is to train positive thinking. Therefore, the present study aimed to investigate positive thinking skills training on anxiety and happiness in the elderly.

Methods: In this quasi-experimental study, 48 elderly people referred to two comprehensive health service centers in Kerman in southeastern Iran were selected by convenience sampling method and randomly assigned into intervention groups $(n=24)$ and control $(n=24)$. The data collection tools included the Beck Anxiety Inventory and the Oxford Happiness Inventory. Questionnaires were filled out before the intervention, then positive thinking training was held in eight sessions of 90 minutes. After training program, the was conducted one month after it, the follow-up tools.

Results: The results showed that the mean score of anxiety before positive thinking training was (13.58 \pm $8.61)$ and (19.25 \pm 11.67$)$ in the intervention and the control group, respectively. After positive thinking training, the mean scores were $(4.50 \pm 4.07)$ and $(15.54 \pm 9.04)$ in the intervention and control group, respectively. After the intervention, which significantly reduced anxiety the intervention, group $(t=8.10$, $\mathrm{P}<0.001)$. The mean score of happiness before the test was $(26.58 \pm 12.40)$ and $(37.91 \pm 5.57)$ in the intervention and control groups, respectively. However, the posttest happiness scores of the intervention and control groups were $(62.91 \pm 4.66)$ and $(35.62 \pm 10.62)$, respectively. The results showed that implementing positive thinking training increased happiness significantly $(t=-4.08, P<0.001)$.

Conclusion: Since positive thinking training effect reducing anxiety and increasing happiness in the elderly. Due to the growing trend of the elderly population, the positive thinking training approach can be used as a suitable, cost-effective, and efficient method in reducing anxiety and increasing happiness in the elderly.

\section{Background}

Today, aging and its consequences have become one of the most common demographic problems [1]. During the aging period, people are at risk of potential threats such as having chronic diseases, loneliness, isolation, and lack of social support [2], and their independence is threatened due to physical and mental disabilities. Therefore, the elderly should be considered due to their age, reduced abilities, and increased vulnerability $[3,2]$. Depression and anxiety are the most common problems that affect all aspects of the health of the elderly [4]. According to epidemiological studies, anxiety among the elderly is between 1.2 and 15\% [5]. Anxiety in the elderly causes insomnia, forgetfulness, feelings of anxiety with symptoms of irritability, sadness, impaired concentration, and change in appetite [6], so any action to optimize their living conditions can reduce other social and family problems as well [4].

However, stressful events hurt the mental health of individuals. People exposed to stress frequently experience more mental and physical problems than others [7]. Studies show that experiencing anxiety 
reduces anxiety and happiness, meaning that the more anxiety a person experiences, the less happy he will be, thus threatening his general health. Negative emotions, such as anger, restrict the individual's mind from producing a defensive reaction against the negative emotions. On the contrary, positive emotions widen the individual's mind to the environmental simulations, created opportunities, increasing creativity and happiness [8]. Happiness includes a positive emotion, life satisfaction, and the absence of negative emotions such as depression and anxiety. Happiness can be a significant variable in the quality of life of the elderly $[5,9]$. Therefore, paying attention to happiness is a mental category essential in making the elderly hopeful [3].

Increasing happiness helps the elderly control their stressful situations and worries and get rid of negative thoughts. For the elderly to distance themselves from loneliness and anxiety, they must believe in living in happiness and enjoy life until the last moments of life [10]. So far, various medication methods have been used to deal with anxiety and reduce depression associated with physical side effects and addiction to drugs. In some cases, non-pharmacological therapies such as worship, massage therapy, exercise, cognitive therapy, muscle relaxation, acupressure, music therapy, and aromatherapy have been used to tranquilize patients. Non-pharmacological methods or complementary therapies are inexpensive, easy, non-invasive, have fewer side effects and risks, and can be used alone or in combination with other pharmacological methods [11]. Training positive thinking is one of the interventions that can affect the psychological health of the elderly [12]. Lack of a positive outlook on life is an essential cause of depression and anxiety [13].

Positive thinking is an intervention that positively affects physical and mental health, increases happiness, and reduces anxiety. Positive thinking is a prerequisite for Educational, Social, and Professional Success [14]. Cambridge Dictionary defined positive thinking as having lots of hope and focusing on the positive aspects or believing in good events [15].

Ahangarzadeh [14] believes that positive thinking plays a vital role in psychological stability and quality of life, reflects a positive attitude, and plays a vital role in protecting people's mental health in case of fear and crisis. Positive thinking can be promoted through psychological interventions, while lack or absence of positive thinking may affect individual attitudes, increasing the symptoms of depression and anxiety. People need to be hopeful, have positive thinking skills, and have mental abilities to prevent disease.

Several studies have examined the effectiveness of positive thinking on psychological variables; for example, Gallagher et al.'s study on middle-aged cancer survivors showed that positive thinking is associated with improved emotion, adaptation, and health [16]. The results of the study by Thadchai et al. [12] showed that employees who are more adaptable, more positive and happier, outperformed in the face of the retirement crisis. In the study of Ahangarzadeh et al., training positive thinking reduces depression, anxiety, and stress in patients with coronary heart disease [14]. Previous studies have shown the effectiveness of positive thinking program increases the hope and quality of sleep of patients with thalassemia major [17]. 
An increase in life expectancy in the world has led to the phenomenon of aging, and the elderly population is growing faster than the entire population, and the weakness and disability of this vulnerable group require special attention and care. Considering that the presence of anxiety and depression in the aging period is inevitable and has adverse effects on the physical and mental health of the elderly, and due to the high level of negative thinking among them, they should be given the necessary attention and support. The effect of positive thinking on improving the quality of life of the elderly can be through positive thinking training. Also, the importance of the present study is that little research is done to investigate the effect of positive thinking training on happiness and reducing anxiety in the elderly. Therefore, the present study was designed and conducted to test the hypothesis that training positive thinking skills positively reduces anxiety and increases happiness in the elderly.

\section{Methods}

\section{Study design and setting}

A quasi-experimental study with pre-test-post-test design and control group was performed on the elderly in comprehensive health service centers of Kerman University of Medical Sciences in the South East of Iran in 2019. We confirm that all methods were performed in accordance with the relevant guidelines and regulations.

\section{Sample size and sampling}

The sample size was estimated based on Rafie and Momeni's study[18] with a 95\% confidence level and $80 \%$ test power; a total of 48 participants were included in the study, 24 in each group. Finally, to ensure the adequacy of the sample size and consider the possible loss and increase the power of a test, a total of 60 participants were included in the study, 30 in each group. Sampling was done in several stages. First, a list of health centers of Kerman was prepared, then two of 10 centers were selected randomly through a lottery. One center was allocated to the control group and the other to the intervention group through a lottery among the two selected centers. Sampling took about 3 months.

Inclusion criteria for the elderly included having an active file in comprehensive health service centers, willingness to participate in the study, not having psychological disorders, behavioural and mental, hearing, speech disorders according to medical records, not using psychotropic drugs, not participating in psychological interventions at the same time (Similar to positive thinking), and being literate. Exclusion criteria included being absent for more than two intervention sessions, hospitalization, or uninterested in continuing the training.

\section{Data collection and intervention}

First, the researcher obtained the list of the elderly registered in the Integrated Health System website from the head of those centers. Then, 60 eligible elderly from centers 1:12 Farvardin (as intervention group) and 2:22Bahman (as the control group) were included in the study by convenience random sampling method; 48 out of 60 elderly completed the study process ( 24 elderly in each group) because 
six intervention group members did not fully participate in positive thinking sessions. Six members of the control group were excluded from the study due to leaving questionnaires incomplete.

In the next step, the elderly's mobile numbers were received, a face-to-face meeting (with a family member) was held at the health center hall if desired. At that meeting, the researcher explained the study's objectives, handed out the consent form, and let the participant sign it if he/she agrees. Then, to start the pre-test, the researcher completed the Demographic Information Questionnaire and the Anxiety and Happiness Questionnaire. So that people can apply what they have learned in their real-life environment this month. Several older adults were referred to the health center to receive services while emphasizing the process of positive thinking in everyday life.

Positive Thinking Training was held in groups of 6, in 8 sessions of 90 minutes (two sessions per week lasting four weeks), in the hall of Training Center No. 1, from 10 a.m. to 12 p.m. by a researcher and a clinical psychologist through a lecture in the presence of the elderly, storytelling and with educational material taken from the educational and therapeutic books on positive thinking and positivity written by Susan Coeliam [19], Seligman[20] and Sayadi et al [21]. The educational content was approved by a clinical psychologist and a senior psychiatric nurse (Table 1). After the researcher's meetings, the elderly questions were answered. After the last positive thinking session, the researcher contacted the elderly once a week and encouraged them to engage in a positive thinking process in daily life. After 4 weeks, the Anxiety and Happiness Questionnaire was completed again by the researcher coordinating a face-to-face meeting with the elderly.

At the end of the study, the instruction booklets were given to the intervention group. The Elderly assigned to the control group received no intervention. 
Table 1

The educational content of positive thinking training

\section{Session Educational content}

S1 Explaining how-to-do, learn the concept of positive thinking, learning the rules that govern groups

S2 Learning how thinking and attitude are formed

S3 Learning negative thoughts and ways to moderate them, positive thinking and its effect on health and longevity

S4 Training positivity by challenging negative thoughts, changing mental images, using constructive language, and revising beliefs.

S5 Teaching positivity by institutionalizing positive thinking strategies in life, continuing to practice positive thinking, positive thinking opportunities by coping with problems that cannot be solved.

S6 Experiencing positive living by building a positive relationship, the health prerequisite of positivity, establishing good relationships with others, and loving from the heart. Also, rehearsing the last session; Paying attention to good or bad memories and exploring ways to reduce depression; Paying attention to the signs of gratitude and appreciation for raising the level of self-esteem and self-confidence for the process of meetings and its impact on individual behaviour

S7 Being positive by learning how to stop thinking, calming down, and changing attitudes, including the need to overcome and fight

Bring Smile to life, building self-confidence, and developing a good exercise habit

\section{Measurements}

In the present study, three data collection tools were used. It took approximately 15 minutes to complete the survey, including the Demographic Information Questionnaire, the Beck Anxiety Inventory (BAI), and the Oxford Happiness Inventory (OHI).

The demographic information questionnaire included age, gender, level of education, salary, marital status, occupation, living or family status. The Anxiety Inventory designed by Dr. Beck et al.(1988) includes 21 questions. Anxiety symptoms are scaled on a 4-point scale of "never grade 0", "mild grade 1", "moderate grade 2", and "severe grade 3". The minimum and maximum scores are 0 and 63 , respectively, indicating no or least anxiety ( $0-7)$, mild anxiety $(8-15)$, moderate anxiety (16-25), and severe anxiety (25-63) [22]. This questionnaire has been standardized by Kaviani and Mousavi (2008) in Iran. The content validity of its content was confirmed, and its reliability was estimated using retest $(r=0.83)$, and internal consistency (alpha $=0.92)[23]$.

The 29-item Oxford Happiness Questionnaire was used to assess participants' happiness. This tool was first developed by Argyle in 2001 [24] and includes 5 areas of life satisfaction (8 items), self-esteem (7 
items), subjective well-being (5 items), self-satisfaction (4 items), and positive affect (5 items).

This questionnaire is designed in a 4-point Likert scale from 0 to 3, Score 0 (always), Score 1 (sometimes), Score 2 (low), Score 3 (not at all). Individuals in this questionnaire get scores between 0 and 87. A score of 87 indicates the highest level of happiness, a score between $42-40$ normal score, and a score of zero indicates dissatisfaction with life and test depression (24). This questionnaire was validated by Alipour et al. 2007. Internal consistency was used to measure the reliability, estimated to be 0.91 by the Cronbach's alpha coefficient $[25,26]$.

\section{Data analysis}

Data were analyzed via SPSS Statistics 22. First, The Kolmogorov-Smirnov test was used to assess the normality of data distribution. Through descriptive statistics (frequency, percentage, mean, standard deviation, minimum and maximum), and inferential statistics (U Mann-Whitney, Chi-square, analysis of covariance, independent $t$-test, and paired $t$-test) to analyze the data used, $p$-value $\leq 0.05$ was considered as the significance level.

\section{Results}

\section{Demographic information}

Most participants were between 60 and 67years old mean age of intervention and control group (66.79 \pm $0.93,66.62 \pm 0.87$ respectively), $50 \%$ male and $50 \%$ female. The results showed that most of the elderly in the intervention and control group had higher than associates degree ( $50 \%, 58.3 \%$, respectively), lowincome $(58.3 \%, 66.7 \%$, respectively), married (79.2\%, 83.3\%, respectively), and $37.5 \%$ lived with their spouses, $20.8 \%$ in the intervention group and $16.7 \%$ in the control group lived alone (Table 2). 
Table 2

Comparison of demographic characteristics of control and intervention groups.

\begin{tabular}{|c|c|c|c|c|c|}
\hline \multirow[t]{2}{*}{$\begin{array}{l}\text { Group } \\
\text { Variable }\end{array}$} & \multicolumn{2}{|c|}{ Intervention $(n=24)$} & \multicolumn{2}{|c|}{$\begin{array}{l}\text { Control } \\
(n=24)\end{array}$} & \multirow[t]{2}{*}{ Test Result } \\
\hline & No. & $\%$ & No. & $\%$ & \\
\hline \multicolumn{6}{|l|}{ Age (year) } \\
\hline \multirow[t]{2}{*}{ Mean \pm SD } & \multirow{2}{*}{\multicolumn{2}{|c|}{$66.79 \pm 0.93$}} & \multirow{2}{*}{\multicolumn{2}{|c|}{$66.62 \pm 0.87$}} & Mann-Whitney \\
\hline & & & & & $U=249, P=0.379$ \\
\hline \multicolumn{5}{|l|}{ Sex } & \multirow{3}{*}{$\begin{array}{l}\chi^{2}=0.76 \\
P=0.38\end{array}$} \\
\hline Female & 12 & 50 & 15 & 62.5 & \\
\hline Male & 12 & 50 & 9 & 37.5 & \\
\hline \multirow[t]{2}{*}{ Education } & & & & & \multirow{2}{*}{$\begin{array}{l}\chi^{2}=0.33 \\
P=0.56\end{array}$} \\
\hline & & & & & \\
\hline Diploma & 10 & 41.7 & 12 & 50 & \\
\hline Higher than diploma & 14 & 58.3 & 12 & 50 & \\
\hline \multicolumn{5}{|l|}{ Income level } & \multirow{3}{*}{$\begin{array}{l}\chi^{2}=0.36 \\
P=0.55\end{array}$} \\
\hline Low & 16 & 66.7 & 14 & 58.3 & \\
\hline Average & 8 & 33.3 & 10 & 41.7 & \\
\hline \multicolumn{5}{|l|}{ Marital status } & \multirow{3}{*}{$\begin{array}{l}X^{2}=0.13 \\
P=0.712\end{array}$} \\
\hline Married & 19 & 79.2 & 20 & 83.3 & \\
\hline Single & 5 & 20.8 & 4 & 16.7 & \\
\hline \multicolumn{5}{|l|}{ Occupation } & \multirow{4}{*}{$\begin{array}{l}\chi^{2}=0.35 \\
P=0.83\end{array}$} \\
\hline Housewife & 10 & 41.7 & 8 & 33.3 & \\
\hline Freelancer & 6 & 25 & 7 & 29.2 & \\
\hline Retired & 8 & 33.3 & 9 & 37.5 & \\
\hline \multicolumn{5}{|l|}{ Living status } & \multirow{5}{*}{$\begin{array}{l}X^{2}=0.25 \\
P=0.96\end{array}$} \\
\hline Alone & 5 & 20.8 & 4 & 16.7 & \\
\hline With spouse & 9 & 37.5 & 9 & 37.5 & \\
\hline Children & 3 & 12.5 & 4 & 16.7 & \\
\hline Spouse and children & 7 & 29.2 & 7 & 29.2 & \\
\hline
\end{tabular}




\section{Anxiety}

Before the intervention, $8.3 \%$ (intervention group), and $25 \%$ of the elderly (control group) had severe anxiety, while after the intervention, this rate reached zero and $16.7 \%$ in the intervention group and the control group, respectively.

The results showed that before the intervention, the mean anxiety scores of both groups were not significantly different $(P=0.062)$, but after the implementation of positive thinking training, the mean anxiety score in the intervention group decreased significantly compared to the control group $(t=-5.45, p$ $<0.001)$. This means that positive thinking skills significantly affected anxiety in the intervention group. Independent t-test analysis test was run to confirm the results (Table 3).

Table 3

Comparison of the mean anxiety score between intervention and control groups in pre-and post-test the positive thinking program

\begin{tabular}{|lllll|}
\hline Variable & Group & $\begin{array}{l}\text { Before the } \\
\text { intervention }\end{array}$ & $\begin{array}{l}\text { After the } \\
\text { intervention }\end{array}$ & $\begin{array}{l}\text { Within the group } \\
\text { statistical estimation }\end{array}$ \\
\hline Anxiety & Intervention & $13.58 \pm 8.61$ & $4.50 \pm 4.07$ & $\mathrm{t}=8.10, \mathrm{P}<0.001$ \\
\cline { 2 - 5 } & Control & $19.25 \pm 11.67$ & $15.54 \pm 9.04$ & $\mathrm{t}=1.75 \mathrm{P}=0.093$ \\
\hline $\begin{array}{l}\text { Between groups estimation } \\
\text { in each section }\end{array}$ & $\mathrm{t}=-1.91$ & $\mathrm{t}=-5.45$ & \\
\hline & $\mathrm{P}=0.062$ & $\mathrm{P}<0.001$ & \\
\hline
\end{tabular}

\section{Happiness}

Table 4 shows the level of happiness and its variables in the study groups before and after the intervention. The results showed that there was a significant difference between the two groups in terms of happiness, and the mean happiness scores in the intervention group were lower than that in the control group before the intervention $(t=-4.08, p<0.001)$. However, in the post-test stage, the mean happiness score in the intervention group increased significantly compared to the control group $(F=-107.73, p<$ 0.001), meaning that the educational intervention had a significant effect on happiness in the intervention group. The mean scores of happiness were significantly different between the two groups ( $P$ $<0.001)$. In addition, the mean scores of the intervention group (62.91 \pm 4.66$)$ were higher than that of the control group (35.62 \pm 10.62$)$, and this difference was statistically significant, Covariance analysis test was come to confirm the results . 
Table 4

Comparison of mean happiness score between intervention and control groups in pre-and post-test the positive thinking program

\begin{tabular}{|c|c|c|c|c|}
\hline $\begin{array}{l}\text { Happiness } \\
\text { Variable }\end{array}$ & Group & $\begin{array}{l}\text { Before } \\
\text { intervention }\end{array}$ & $\begin{array}{l}\text { One month } \\
\text { after the } \\
\text { intervention }\end{array}$ & $\begin{array}{l}\text { Within the group } \\
\text { Statistical Estimation }\end{array}$ \\
\hline \multirow[t]{5}{*}{ Satisfaction } & Intervention & $7.79 \pm 5.18$ & $15.29 \pm 3.82$ & $t^{*}=-4.968 P<0.001$ \\
\hline & \multirow[t]{2}{*}{ Control } & \multirow{2}{*}{$\begin{array}{l}11.54 \pm \\
3.45\end{array}$} & \multirow[t]{2}{*}{$8.95 \pm 5.21$} & $t^{\star}=2.29$ \\
\hline & & & & $P=0.031$ \\
\hline & \multirow{2}{*}{$\begin{array}{l}\text { Between groups } \\
\text { estimation in each section }\end{array}$} & $t * \star=-2.95$ & $F^{\star \star \star}=17.68$ & \\
\hline & & $P=0.005$ & $P<0.001$ & \\
\hline \multirow[t]{6}{*}{ Self-Esteem } & \multirow[t]{2}{*}{ Intervention } & \multirow[t]{2}{*}{$6.37 \pm 3.09$} & \multirow[t]{2}{*}{$14.25 \pm 1.89$} & $t^{*}=-11.12$ \\
\hline & & & & $P<0.001$ \\
\hline & \multirow[t]{2}{*}{ Control } & \multirow[t]{2}{*}{$8.33 \pm 1.49$} & \multirow[t]{2}{*}{$7.75 \pm 2.90$} & $t^{\star}=0.84$ \\
\hline & & & & $P=0.409$ \\
\hline & \multirow{2}{*}{$\begin{array}{l}\text { Between groups } \\
\text { estimation in each section }\end{array}$} & $t^{\star \star}=-2.795$ & $F^{\star \star \star}=70.845$ & \\
\hline & & $P=0.008$ & $P<0.001$ & \\
\hline \multirow{4}{*}{$\begin{array}{l}\text { Subjective } \\
\text { Wellbeing }\end{array}$} & Intervention & $5.29 \pm 3.55$ & $11.91 \pm 1.44$ & $t^{*}=-10.8, P<0.001$ \\
\hline & Control & $7.41 \pm 1.10$ & $7.01 \pm 3.51$ & $t^{\star}=0.577 P=0.570$ \\
\hline & \multirow{2}{*}{$\begin{array}{l}\text { Between groups } \\
\text { estimation in each section }\end{array}$} & $t^{\star \star *}=-2.796$ & $F * \star *=43.546$ & \\
\hline & & $P=0.008$ & $P<0.001$ & \\
\hline \multirow{5}{*}{$\begin{array}{l}\text { Self- } \\
\text { Satisfaction }\end{array}$} & Intervention & $2.95 \pm .1 .39$ & $9.91 \pm 1.10$ & $t^{*}=-23.36 P<0.001$ \\
\hline & \multirow[t]{2}{*}{ Control } & \multirow[t]{2}{*}{$3.62 \pm 1.76$} & \multirow[t]{2}{*}{$5.25 \pm 2.40$} & $t^{\star}=2.18$ \\
\hline & & & & $P=0.039$ \\
\hline & \multirow{2}{*}{$\begin{array}{l}\text { Between groups } \\
\text { estimation in each section }\end{array}$} & $t^{\star \star}=-1.451$ & $t \star \star=8.65$ & \\
\hline & & $P=0.154$ & $P<0.001$ & \\
\hline \multirow{3}{*}{$\begin{array}{l}\text { Positive } \\
\text { Mood }\end{array}$} & Intervention & $4.16 \pm 2.69$ & $11.54 \pm 1.10$ & $t=-15.584 P<0.001$ \\
\hline & Control & $\begin{array}{l}7.01 \pm \\
0.083\end{array}$ & $6.66 \pm 3.71$ & $t=0.467 P=0.645$ \\
\hline & $\begin{array}{l}\text { Between groups } \\
\text { estimation in each section }\end{array}$ & $\begin{array}{l}t^{\star \star *}=-4.916 \\
P<0.001\end{array}$ & $\begin{array}{l}F^{* \star \star *}=37.093 \\
P<0.001\end{array}$ & \\
\hline
\end{tabular}




\begin{tabular}{|lllll|}
\hline $\begin{array}{l}\text { Happiness } \\
\text { Variable }\end{array}$ & Group & $\begin{array}{l}\text { Before } \\
\text { intervention }\end{array}$ & $\begin{array}{l}\text { One month } \\
\text { after the } \\
\text { intervention }\end{array}$ & $\begin{array}{l}\text { Within the group } \\
\text { Statistical Estimation }\end{array}$ \\
\hline Happiness & Intervention & $26.8 \pm$ & $62.91 \pm 4.66$ & $t^{\star *}=-113.93 \mathrm{P}<0.001$ \\
\cline { 2 - 5 } & $\begin{array}{l}12.40 \\
\text { Control }\end{array}$ & $\begin{array}{l}37.91 \pm \\
5.57\end{array}$ & $35.62 \pm 10.62$ & $\mathrm{t}^{*}=1.06 \mathrm{P}=0.297$ \\
& $\begin{array}{l}\text { Between groups } \\
\text { estimation in each section }\end{array}$ & $\begin{array}{l}\mathrm{t}^{* *}=-4.08 \\
\mathrm{P}<0.001\end{array}$ & $\begin{array}{l}\mathrm{F}^{* * *}=-107.73 \\
\mathrm{P}<0.001\end{array}$ & \\
\hline
\end{tabular}

* Paired t-test, ** Independent t-test, *** Covariance analysis test

\section{Discussion}

The present study aimed to evaluate the effect of positive thinking training on anxiety and happiness of the elderly.

The findings supported the research hypothesis showing that anxiety and happiness scores of the intervention group increased significantly at the posttest.

The study results indicate a significant difference between the mean score of anxiety after positive thinking training programs in the intervention group. This obvious statistical difference between the scores before and after the intervention in the studied samples results from implementing a positive thinking training model on the samples of the intervention group, which has significantly reduced the anxiety of the elderly. Numerous studies have confirmed the effectiveness of this training. For example, training positive thinking skills dramatically affects self-efficacy and self-confidence, reducing anxiety, stress, and occupational burnout in nurses [21].

In the study of Nikmanesh and Zandukil, Positive thinking training effectively reduced the mean score of depression, anxiety, stress and improved the quality of life of adolescents[27]. In the study of Ahangarzadeh Rezaei et al. (2017), positive thinking training reduced depression, anxiety, and stress in patients with coronary heart disease [14]. The results of Layous et al.'s study [28] showed that positive psychotherapy is effective in reducing depression symptoms and increasing happiness in different cultures. Farnam (2016), in another study, showed that positive thinking training increases the elderly's quality of life and life span [29].

Oliveira et al.'s study[30] showed that the higher the level of positive thinking, the significantly lower the stress level of the elderly. Puig-Perez et al. [31] concluded that more positive thinking led to better adaptation to the stressful situation of the aging period, while negative thinking led to maladaptation. Ahmad \& Gaber [32] reported that positive thinking reduces death anxiety in elderly patients. On the other hand, Shokrpour et al. showed that positive thinking training had no significant effect on the anxiety of haemodialysis patients [33]. Perhaps one of the reasons for the inconsistency of the results of this study 
with the present study is differences in participants in the positive thinking program. While in the present study, the training program has a significant effect on anxiety.

The results showed that positive thinking training could increase the mean score of happiness in the intervention group. In confirmation of this result, Sohani and Irani's study [34] showed that positive thinking skills training has a positive effect on self-care, happiness, and self-efficacy in the elderly. Sohrabi and Jafari's study [35] showed that positive psychotherapy group has been effective in increasing resilience, happiness, and general health. Haroon Rashidi and Bahiraei [36] showed that positive thinking training increased happiness and life satisfaction in older men. On the other hand, results of the study by Tavakoli et al. [37] and Ho et al.[38] showed that positive thinking interventions have been effective on happiness, depression, and life satisfaction in the elderly [39].

The findings of this study highlight the importance of positive thinking approaches to anxiety and happiness in the elderly. The elderly experience many stressful conditions, therefore positive approach focuses on the talents' strengths and motivates the elderly to achieve the desired result regardless of their circumstances. In addition, optimism can help them overcome stressful problems and improves their quality of life and happiness in the elderly.

\section{Limitations}

In the present study, data were followed up in two stages due to the prevalence of Covid-19, and it is suggested that studies be performed with long-term training and interventions. Follow-ups should be done after the intervention with longer intervals (three months, six months).

\section{Conclusions}

According to the present study results, positive thinking training in the elderly leads to learning the necessary positive thinking skills and reality-based flexibility. This makes them physically and mentally adaptable to problems and issues, especially in the coronavirus pandemic where the elderly experienced anxiety. Therefore, it is recommended that psychiatrists, psychologists, clinical nurses, nursing home officials, and all elderly caregivers provide psychological protection to the elderly against various injuries and problems. They use positive thinking skills training programs in their treatment as a nonpharmacological method to prevent psychological problems such as anxiety and make the elderly happy.

\section{Abbreviations}

SPSS: Statistical Package for the Social Sciences; OHI: Oxford Happiness Inventory. BAl: Beck Anxiety Inventory.

\section{Declarations}

\section{Acknowledgments}


The researchers appreciate the Comprehensive Health Service Centers officials and the elderly and their families who assist them in this study.

\section{Authors' contributions}

AP, JF, SKs, and MAf contributed to conceiving and designing the research. . Data was collected by, AP. Data analysis and interpretation were done by AP, SKs, and JF also, participated in data interpretation. AP conducted the intervention. SKs, MAf and JF participated in drafting the manuscript.AP, SKs, MAf and JF revised the manuscript critically for important intellectual content and final approval of the manuscript. All authors read and approved the final manuscript.

\section{Funding}

This research received no specific grant from any funding agency in the public, commercial, or not-forprofit sectors

\section{Availability of data and materials}

The data are available upon request to the corresponding author after signing appropriate documents in line with ethical application and the decision of the Ethics Committee

\section{Ethics approval and consent to participate}

This paper was extracted from the dissertation of a master's degree student in community health nursing (project number 98000924). The Ethics Committee approved it of Kerman University of Medical Sciences (ethics code: IR.KMU.REC.1398.606) and the objectives of the study were explained to the participants. All participants signed written informed consent after obtaining verbal and written and confidentiality of the information was assured.

\section{Consent for publication}

Not applicable

\section{Conflicts of Interest}

The authors declare that there is no conflict of interest

\section{References}

1. Jiménez MG, Montorio I, Izal MJDp. The association of age, sense of control, optimism, and selfesteem with emotional distress. 2017;53(7):1398.

2. Mosavi SV, Mahfeli M, Rezaei S, Poorabolghasem Hosseini S. The Effectiveness of Laughter Therapy on the Hope and Pain Intensity in Elderly. Aging Psychology. 2018;4(1):1-12. 
3. Kiljunen O, Partanen P, Välimäki T, Kankkunen P. Older people nursing in care homes: An examination of nursing professionals' self-assessed competence and its predictors. International journal of older people nursing. 2019;14(2):e12225.

4. Afshan Ghasemi AA. The Effectiveness of Snyder Hope Theory on Group Happiness in Elderly Happiness. Sid. 2017;41:17- 40.

5. Oraki M, Mehdizadeh A, Dortaj A. The Effectiveness of Self-care Empowerment Training on Life Expectancy, Happiness and Quality of Life of the Elderly in Iranian Elderly Care Centers in Dubai \%J Salmand: Iranian Journal of Ageing. 2019;14(3):320-31 (persion). doi:10.32598/sija.13.10.670.

6. Indarwati R, Fauzi A, Asmoro CPJSRiP. The Effect of Reminiscence Therapy on The Level of Anxiety for Elderly People. 2020;11(3):793-6.

7. Arman M. The comparison of depression, anxiety and stress between active and inactive old women in Isfahan. J Rehab Med. 2014;3(3):82-8.

8. Kahrazei F, Akbarizadeh A. Comparison of the general health and happiness of the elderly living in nursing homes, private homes with and without family-based rehabilitation Services. Journal of Gerontology. 2020;4(3):56-67.

9. Zhang Y, Han BJPj. Positive affect and mortality risk in older adults: A meta-analysis. 2016;5(2):12538.

10. Jafari A, Behboodi M. The Efficacy of Aerobic Exercises in Reducing Loneliness and Promoting Happiness in Elderly \%J Journal of Nursing Education. 2017;5(5):9-17 (persion). doi:10.21859/ijpn05052.

11. Hashemi Siyavoshani M, Fallahi Arezodar F, Pishgooei SA, Jadid_milani M. The effect of rose water on the anxiety level of aged admitted to cardiac intensive care units \% J Iranian Journal of Nursing Research. 2020;15(1):59-68 (persion).

12. Thadchai N, Suksawat J, Wongtim S. Adaptation, Positive Thinking, and Happiness in Work Performance Affecting Preparation to Enter Elderly Social Society. HUMAN BEHAVIOR, DEVELOPMENT and SOCIETY. 2018;19:105-12.

13. Ajlouni AO, Almahaireh AS. Relationship between coronavirus-related anxiety and optimism among undergraduates at the University of Jordan. Education. 2012;2015.

14. Ahangarzadeh Rezaei S, Nematolahei A, Oladrostam NJTJUNMF. The effect of positive thinking training on stress, anxiety and depression in coronary heart disease. 2017;15(5):339-48 (persion).

15. Marton G, Monzani D, Vergani L, Pizzoli SFM, Pravettoni G. "Optimism is a strategy for making a better future": A systematic review on the associations of dispositional optimism with health-related quality of life in cancer patients. European Psychologist. 2020.

16. Gallagher MW, Long LJ, Richardson A, D'Souza JMJCt, research. Resilience and coping in cancer survivors: The unique effects of optimism and mastery. 2019;43(1):32-44.

17. Makaremnia S, Manshadi MD, Khademian Z. Effects of a positive thinking program on hope and sleep quality in Iranian patients with thalassemia: a randomized clinical trial. BMC psychology. 2021;9(1):1-10. 
18. Rafiee Z, Momeni KJIJoBS. The Effectiveness of Optimist Memory Telling on Death Anxiety and the Sense of Aging in Elderly. 2018;12(2):69-75.

19. Moeini B, Barati M, Farhadian M, Ara MHJKjofm. The association between social support and happiness among elderly in Iran. 2018;39(4):260.

20. Seligman ME. Positive psychology in practice. John Wiley \& Sons; 2012.

21. SAYADI SM, HOJATKHAH SM, RASHIDI A. The effectiveness of positive thinking skills on enhancement of psychological well-being and decreased of loneliness in elderly women. 2016.

22. Steer RA, Beck AT. Beck Anxiety Inventory. 1997.

23. Kaviani H, Mousavi AJTUMJTP. Psychometric properties of the Persian version of Beck Anxiety Inventory (BAI). 2008;66(2):136-40.

24. Hills $P$, Argyle MJP, differences i. The Oxford Happiness Questionnaire: a compact scale for the measurement of psychological well-being. 2002;33(7):1073-82.

25. Alipoor a, Noorbala aaJIJoP, Psychology C. A preliminary evaluation of the validity and reliability of the Oxford happiness questionnaire in students in the universities of Tehran. 1999;5(1):55-66.

26. Alipour A, Agah Heris MJJolp. Reliability and validity of the Oxford Happiness Inventory among Iranians. 2007;3(12):287-98.

27. Nikmanesh Z, Zandvakili M. The effect of positive thinking training on quality of life, depression, stress and anxiety in delinquent juveniles. Positive psychology research. 2015;1(2):64-53.

28. Layous K, Lee H, Choi I, Lyubomirsky S. Culture matters when designing a successful happinessincreasing activity: A comparison of the United States and South Korea. Journal of Cross-Cultural Psychology. 2013;44(8):1294-303.

29. Farnam AJPP. The effect of positive thinking training in enhancement of quality and hope of life among the elderly. 2016;2(1):75-88 (persion).

30. Oliveira NAd, Souza ÉN, Luchesi BM, Inouye K, Pavarini SCIJRbde. Stress and optimism of elderlies who are caregivers for elderlies and live with children. 2017;70(4):697-703.

31. Puig-Perez S, Villada C, Pulopulos MM, Almela M, Hidalgo V, Salvador AJIJoP. Optimism and pessimism are related to different components of the stress response in healthy older people. 2015;98(2):213-21.

32. Ahmad AA, Gaber OHJIJoPS. The relationship between death anxiety, level of optimism and religiosity among adult cancer patients: A predictive study. 2019;11(1):26-35.

33. Shokrpour N, Sheidaie S, Amirkhani M, Bazrafkan L, Modreki A. Effect of positive thinking training on stress, anxiety, depression, and quality of life among hemodialysis patients: A randomized controlled clinical trial. Journal of Education and Health Promotion. 2021;10.

34. Sohani A, Barghi Irani Z. Effectiveness of psychological rehabilitation based on training of positive thinking skills on self-care, happiness and self-efficacy in elderly people with type 2 diabetes. Aging Psychology. 2018;4(3):235-49. 
35. Sohrabi F, Jafari Roshan F. Effectiveness of positive group psychotherapy on resiliency, happiness and general health on women with a substance dependence spouses. Positive Psychology Research. 2016;2(1):31-46.

36. Haroon Rashidi $\mathrm{H}$, Bahiraei MR. The Effectiveness of positivism training on the life satisfaction and character strengths in the elderly men. Aging Psychology. 2020;6(2):179-89.

37. Tavakoli G, Rezai Dehnavi S, Montajabian Z. The Effectiveness of Positive Psychotherapy on the Vitality in the Elderly. Aging Psychology. 2021;6(4):308-299.

38. Ho HC, Yeung DY, Kwok SY. Development and evaluation of the positive psychology intervention for older adults. The Journal of Positive Psychology. 2014;9(3):187-97.

39. Leontopoulou S. A positive psychology intervention with emerging adults. The European Journal of Counselling Psychology. 2015;3(2):113-36. 